Revista de Comunicación y Salud, 2022 Vol. 12, 1-23

Editado por Cátedra de Comunicación y Salud

ISSN: 2173-1675

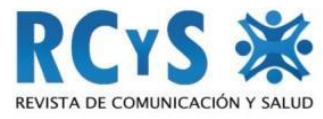

Enviado 13/07/2021

Aprobado 25/10/2021

Publicado 03/01/2022

\title{
CONTENIDOS DIGITALES EN LA ERA DE TIKTOK: PERCEPCIÓN DE LOS USUARIOS DEL BOTÓN COVID-19 EN ESPAÑA
}

\section{Digital content in the age of TikTok: user perception of the Covid-19 Button in Spain}

\author{
Juan Pablo Micaletto-Belda. \\ Centro Universitario San Isidoro. España. \\ imicaletto@centrosanisidoro.es \\ Pablo Martín-Ramallal. \\ Centro Universitario San Isidoro. España. \\ pmartin@centrosanisidoro.es
}

\author{
Alba Merino-Cajaraville. \\ Centro Universitario San Isidoro. España. \\ amerino@centrosanisidoro.es
}

\section{Cómo citar el artículo}

Micaletto-Belda, J-P., Martín-Ramallal, P. y Merino-Cajaraville, A. (2022). Contenidos digitales en la era de tiktok: percepción de los usuarios del botón COVID-19 en España. Revista de Comunicación y Salud, 12, 1-23. http://doi.org/10.35669/rcys.2022.12.e290

\section{Resumen}

El Covid-19 ha provocado una crisis sanitaria, a nivel global, que ha irrumpido con profundas implicaciones sociales, culturales, económicas y comunicativas (CastilloEsparcia, Fernández-Souto; Puentes-Rivera, 2020). Las redes sociales han demostrado ser un medio de comunicación idóneo y fundamental para transmitir información clave sobre asuntos de interés general (Cancelo; Gadea, 2013). Estas plataformas adquieren 
un papel determinante en la pandemia. TikTok, una de las redes emergentes de los últimos dos años, incorporó, en su versión móvil, el botón Covid-19; una herramienta diseñada para ayudar a su comunidad a protegerse del coronavirus. La iniciativa consiste en resolver dudas y compartir información, con los miembros de la comunidad, basada en el cumplimiento de las recomendaciones sanitarias (lavado de manos frecuente, uso de mascarilla, etc.) emitidas por el Ministerio de Sanidad, en España, y la Organización Mundial de la Salud. La investigación plantea como objeto de estudio el análisis de la percepción pública que poseen los usuarios de TikTok sobre esta herramienta y de los recursos disponibles en su versión española, con el objetivo de determinar cómo perciben estos contenidos, así como su utilidad. Con este propósito se ha diseñado una metodología mixta, compuesta por un análisis cuantitativo y cualitativo, que se ha materializado a través de una encuesta en línea dirigida a un grupo de prosumidores de la plataforma. Los resultados reflejan que estos individuos valoran de forma favorable los contenidos digitales compartidos en TikTok. No obstante, señalan que sería necesario mejorar el diseño y la adaptación de estos recursos a la plataforma y al público tipo, como se expresa en las fuentes consultadas en el artículo (Marcelino, 2015; De-las-Casas, 2020). Por ende, la investigación revela que no se está aprovechando plenamente el potencial de esta herramienta de comunicación para ofrecer información de interés general sobre el coronavirus. Finalmente, se plantean futuras líneas de investigación en el trabajo, como conocer la funcionalidad de iniciativas similares en otras redes sociales o analizar los mensajes de TikTok difundidos por las instituciones públicas.

Palabras clave: Redes sociales, coronavirus, Covid-19, pandemias, TikTok, contenidos digitales, comunicación, publicidad institucional, crisis, accesibilidad

\section{Abstract}

Covid-19 has provoked a global health crisis that has had profound social, cultural, economic and communicative implications (Castillo-Esparcia; Fernández-Souto; Puentes-Rivera, 2020). Social networks have proven to be an ideal and fundamental means of communication for transmitting key information on matters of general interest (Cancelo; Gadea, 2013). For this reason, these platforms acquire a determining role in the pandemic. TikTok, one of the emerging networks of the last two years, has introduced, in its mobile version, the Covid-19 button; a tool designed to help its community to protect themselves and others from the coronavirus. The initiative consists of resolving doubts and sharing information with members of the community, based on compliance with health recommendations (frequent hand washing, use of masks, etc.) issued by the Spanish Ministry of Health and the World Health Organization. The purpose of the research is to analyze the public perception of TikTok users about this tool and the resources available in its Spanish version, with the aim of determining how they value these contents, as well as their usefulness. For this purpose, a mixed methodology has been designed, consisting of a quantitative and qualitative analysis, which has materialized through an online survey addressed to a group of prosumers of 
Contenidos digitales en la era de TikTok: percepción de los usuarios del botón COVID-19 en España

the platform. The results reflect that these individuals favorably value the digital content shared on TikTok. However, they point out that it would be necessary to improve the design and adaptation of these resources to the platform and the target audience, as expressed in the sources consulted in the article (Marcelino, 2015; De-las-Casas, 2020). Therefore, the investigation reveals that the potential of this communication tool to offer information of general interest about the coronavirus is not being fully exploited. Finally, future lines of research at work are proposed, such as knowing the functionality of similar initiatives in other social networks or analyzing the TikTok messages disseminated by public institutions.

Keywords: Social networks, coronavirus, Covid-19, pandemics, TikTok, digital content, communication, institutional publicity, crisis, accessibility, design

\section{INTRODUCCIÓN}

La crisis provocada por el SARS-CoV-2 está transformando el ecosistema comunicativo en el que operan las marcas, las agencias de publicidad y los anunciantes (Xifra, 2020). Las empresas y las instituciones buscan una nueva forma de comunicar y transmitir para relacionarse con sus públicos de interés, especialmente en los entornos digitales (De-las-Casas, 2020).

En el ámbito empresarial, la publicidad basada en la comercialización masiva de productos y servicios está siendo sustituida paulatinamente por una comunicación de corte corporativo alineada con la situación actual que vive la población. La finalidad de esta nueva forma de comunicar es mantener y mejorar la reputación de las marcas, con mensajes de esperanza y tranquilidad dirigidos a los ciudadanos (Suarez, 2020).

A nivel institucional, los diferentes gobiernos, haciendo un llamamiento a la responsabilidad, están desarrollando diversas acciones comunicativas que, con mayor o menor éxito, tratan de frenar la expansión del coronavirus y proteger la salud de las personas a través de campañas publicitarias o la difusión de determinados contenidos en las redes sociales. Estas iniciativas tratan de promocionar hábitos basados en el uso obligatorio de mascarillas, el lavado de manos frecuente o el distanciamiento de seguridad en los lugares públicos (Moreno, 2020).

Las redes sociales representan un canal de comunicación clave para transmitir información a la población sobre asuntos de interés público (Cancelo; Gadea, 2013). Por esta razón, las instituciones están multiplicando su presencia en estos entornos virtuales para amplificar su voz y trasladar a la población la importancia de respetar las recomendaciones sanitarias. En España, el Ministerio de Sanidad (2020) está presente en redes como Facebook, Twitter, Instagram, Telegram o YouTube y, recientemente, ha creado un perfil en TikTok, con el objetivo de conectar con las personas más jóvenes.

Esta plataforma, que está revolucionando el panorama actual de las redes sociales, ha experimentado un profundo crecimiento durante el último año y representa una de las redes sociales más empleadas entre los integrantes de la generación Z (IAB, 2020; 
Contenidos digitales en la era de TikTok: percepción de los usuarios del botón COVID-19 en España

IAB, 2021). La red se basa en la edición y difusión de vídeos, de corta duración, que pueden alcanzar un importante número de visualizaciones gracias a su algoritmo. Actualmente, cuenta con 1500 millones de usuarios activos. Además, está operativa en 155 países y disponible en 75 idiomas (Mohsin, 2021).

Debido a su alcance, Tiktok se ha convertido en un instrumento con potencial para concienciar a la población sobre el coronavirus y frenar su propagación (Verne, 2020). La plataforma habilitó, en su aplicación móvil, el botón Covid-19, una sección destinada a ofrecer información veraz y contrastada sobre el coronavirus, en colaboración con el Ministerio de Sanidad y la Organización Mundial de la Salud. La iniciativa, de índole altruista, consiste en resolver dudas y compartir contenidos digitales relacionados con medidas de seguridad y prevención en un escenario de incertidumbre.

En este contexto de crisis, es necesario plantearse la eficacia que estas nuevas iniciativas adquieren entre los ciudadanos y si resultan adecuadas para lograr sus objetivos. Por esta razón, esta investigación se centra en el análisis de la percepción pública que poseen los usuarios de TikTok sobre el botón Covid-19 y de los recursos disponibles en su versión española. La finalidad del estudio es determinar cómo valoran los usuarios los contenidos, de carácter publicitario e informativo, que forman parte de esta sección de la aplicación móvil.

Esta distopía causada por el coronavirus ha generado un terremoto sin precedentes que está provocando recesiones económicas, estallidos sociales y conflictos políticos que afectan de forma simultánea a múltiples países (Sterzer, 2020). Las diferentes autoridades públicas, en un intento de controlar la pandemia, están haciendo uso de diferentes plataformas y herramientas comunicativas para prevenir a la sociedad de los riesgos derivados del virus. La comunicación, desde un punto de vista estratégico, está adquiriendo una nueva dimensión en este contexto de crisis global.

Los poderes públicos se enfrentan al desafío de conectar, mediante la comunicación institucional y la publicidad, con un público que, debido a la multiplicidad de canales informativos y de entretenimiento, se encuentra disperso en diversas plataformas y medios que omiten mensajes de carácter persuasivo (Selva-Ruiz; Martín-Ramallal, 2019). A este hecho se suma, además, la profunda proliferación de mensajes publicitarios que dificulta seriamente la capacidad receptiva de las masas (Orozco, 2010).

La comunicación ha adquirido un papel trascendental en la transmisión de información preventiva sobre el coronavirus. Sin embargo, se evidencia que en medios sociales como Instagram, Facebook y YouTube no ha obtenido el impacto deseado (Igartua, Ortega-Mohedano; Arcila-Calderón, 2020). Por este motivo, resulta de interés indagar en la percepción de los jóvenes de esta sección de TikTok, pues según los datos consultados con anterioridad se trata de una red emergente en pleno crecimiento (IAB, 2020; Mohsin, 2021). Es necesario desarrollar, desde un punto de vista académico, estudios que permitan reflexionar sobre la eficacia de estas herramientas comunicativas, ofreciendo, llegado el caso, propuestas que permitan mejorar la calidad 
Contenidos digitales en la era de TikTok: percepción de los usuarios del botón COVID-19 en España

y la eficacia de la información ofrecida sobre asuntos de interés social: pandemias, catástrofes, etc.

El artículo explica los principales fundamentos teóricos que forman parte de la publicidad institucional. Después, se analiza el papel que poseen las redes sociales en el diseño y la difusión de contenidos digitales. Esta revisión teórica sirve de base para analizar el apartado de la aplicación de TikTok "Medidas de protección", que recoge anuncios publicitarios de carácter institucional, y "Preguntas y respuestas" que incluye información sobre el SARS-CoV-2, ambas incluidas en "Botón Covid-19" de esta plataforma. A continuación, se detalla la metodología empleada para alcanzar el propósito del estudio. Seguidamente, se analizan los resultados obtenidos mediante las técnicas cuantitativas y cualitativas y se abre un proceso de discusión en el que se relaciona la teoría abordada con los datos alcanzados. Finalmente, la investigación cierra con las conclusiones y la bibliografía empleada.

\subsection{La publicidad institucional en contextos de crisis}

La publicidad institucional es una forma de comunicación persuasiva diseñada con el propósito de transmitir valores a la población. Los poderes públicos (el Estado, las Comunidades Autónomas, las Provincias y los Ayuntamientos) emplean esta herramienta de marketing para difundir mensajes propagandísticos sobre asuntos de interés público (Martínez, 2012; Martínez, 2015).

El término institucional refleja la legitimidad y oficialidad que poseen los mensajes pronunciados por las autoridades públicas (Bassat, 2006). Por otra parte, la palabra publicidad hace referencia a cualquier forma de comunicación destinada a promocionar ideas, productos o servicios por parte de un determinado anunciante (Kotler; Armstrong, 2013).

En su conjunto, esta fórmula de comunicación representa "una forma (de las más importantes) de existencia del Estado (ya que el Estado es algo que no podemos percibir sino a través de sus símbolos, y existe como se hace ver y oír por los ciudadanos)" (Cortés, 2011, p.7). Es obligación de un Estado democrático garantizar el derecho de sus ciudadanos de recibir información veraz desde los poderes públicos (Aguado-Guadalupe, 2018) con objeto de alentarla, prevenirla o protegerla sobre asuntos de interés general (Martínez, 2015).

La Ley 29/2005, de 29 de diciembre, de Publicidad y Comunicación Institucional, señala que esta forma de comunicación debe servir al "estricto servicio de las necesidades e intereses de los ciudadanos, facilitar el ejercicio de sus derechos y promover el cumplimiento de sus deberes" (p.3). En la actualidad, constituye "toda actividad orientada y ordenada a la difusión de un mensaje u objetivo común, dirigida a una pluralidad de destinatarios, que utilice un soporte publicitario pagado o cedido y sea promovida o contratada por alguno de los sujetos enunciados" (p.4). La publicidad institucional respeta los mismos principios y reglas que la publicidad comercial. No obstante, su grado de trascendencia y su impacto en la sociedad es mayor (Bassat, 2006); pues constituye una herramienta que se emplea "tanto para vender Coca-Cola 
Contenidos digitales en la era de TikTok: percepción de los usuarios del botón COVID-19 en España

en todo el orbe como para educar a los pueblos en desarrollo sobre cómo prevenir la propagación del VIH/SIDA" (Kotler; Armstrong, 2013, p. 365).

Esta comunicación posee una doble vertiente basada en la información y la persuasión. El anunciante emite mensajes con información de interés general para la ciudadanía sobre un problema concreto que, al mismo tiempo, posee una intencionalidad persuasiva (Martínez, 2015). En su conjunto, estos mensajes están diseñados para mantener, reforzar o cambiar determinadas actitudes de las personas que permitan mejorar la sociedad y propiciar una determinada imagen de marca de un organismo público (Cortés, 2009). En consecuencia, los mensajes publicitarios idóneos deberán de hacer uso de la razón y la emoción para interaccionar con el receptor (Bassat, 2006).

La publicidad es una forma de comunicación dirigida a un público meta que cuenta con una serie de objetivos prefijados. En relación a los propósitos del anunciante emisor, la comunicación publicitaria cumple principalmente tres funciones básicas: informar, persuadir y recordar (Kotler; Armstrong, 2013; Monferrer, 2013).

La publicidad institucional adopta diferentes formas según los objetivos planteados por el emisor de la comunicación: educativo-social, comercial, informativa y electoral. Educativa: se centra en la función socializadora del estado, mediante campañas destinadas a transmitir valores y provocar cambios de conducta en los ciudadanos. Informativa: ofrece una serie de indicaciones a la población relacionadas con el reciclaje, trámites administrativos o situaciones de emergencia. Comercial: busca atraer clientes para un mercado relacionado con el país, como es el caso de las campañas de promoción del turismo. Electoral: vinculada con la participación ciudadana en los procesos democráticos (Cortés, 2011).

Por otro lado, una crisis representa un acontecimiento extraordinario que afecta a la imagen y al equilibrio externo de la institución ante sus stakeholders (Piñuel, 1997). Esta situación provoca un cambio que genera un problema urgente que exige de la atención de los poderes públicos (Castillo-Esparcia, 2010; Luecke, 2005). Gallardo-Vera y Micaletto-Belda explican que en una situación de crisis la institución "debe establecer relaciones informativas de calidad con todos sus públicos internos y externos mediante una gestión de signos, mensajes, discursos y sentidos adecuada a las actitudes que se van formando en los públicos durante el decurso de la crisis" (2018, p. 451).

Sobre este aspecto, Xifra (2020) señala que "en tiempos del Covid-19 no hay que comunicar de cualquier manera. Las organizaciones y las marcas deben comunicar con emoción, con compasión y con hechos" (p.11). 
Contenidos digitales en la era de TikTok: percepción de los usuarios del botón COVID-19 en España

\subsection{Redes sociales y TikTok: nuevas formas de comunicar}

En situaciones de crisis, las redes sociales facilitan la comunicación entre los usuarios y generan un sentimiento de comunidad (Olivares-García; Méndez-Majuelos, 2020). Flores-Vivar (2009) las define como "un lugar de encuentro, de reuniones de amigos o personas que tienen intereses comunes" (p. 74). Estas plataformas permiten a los usuarios relacionarse, mantenerse en contacto y compartir toda clase de información (Orihuela-Colliva, 2008). En su conjunto, representan una ruptura del tradicional proceso comunicativo del emisor-receptor, posibilitando que un usuario llegue a una gran audiencia a través de internet (Cancelo; Almansa, 2013) en un proceso basado en la autocomunicación de masas (Castells, 2009).

Estos medios de socialización permiten a los jóvenes construir y proyectar una determinada imagen mediante la difusión de contenidos originales que buscan generar impacto (Almansa-Martínez, Fonseca-Bogotá; Castillo-Esparcia, 2013). Los denominados nativos digitales conviven en estas comunidades en línea y demandan contenidos y usos ajustados a su personalidad e intereses. Por tanto, las marcas que desean conectar con sus públicos deben adaptar sus contenidos publicitarios 0 informativos al canal, al tipo de público y al universo cultural de la sociedad (Marcelino, 2015; De-las-Casas, 2020; Cancelo; Gadea, 2013).

En el caso de TikTok, durante el confinamiento provocado por el Covid-19, se convirtió en la aplicación móvil más descargada y usada (Tamara, 2020). Entre los factores que han contribuido a su éxito destacan: la facilidad de registro, la variedad de contenidos y temáticas (retos, recetas de cocina, contenidos musicales, transmisiones en directo, adquisición de productos, contenidos publicitarios, etc.) el diseño simple y atractivo, la facilidad de creación de vídeos con importantes niveles de creatividad y su algoritmo. En relación a este último aspecto, la plataforma aprende de los gustos de cada usuario, diseñando una experiencia única que adapta los contenidos a cada persona, aprendiendo de sus gustos y hábitos de consumo. La aplicación emplea el machine learning para recoger información sobre los vídeos que gustan a cada usuario, los comentarios realizados, el contenido creado o las cuentas a las que siguen. Al mismo tiempo, favorece que cualquier prosumidor pueda viralizar sus vídeos de manera sencilla incluso sin contar con un elevado número de suscriptores. Además, cabe destacar que no es necesario completar un registro para acceder a la plataforma y disfrutar de sus contenidos. Este hecho permite a los creadores llegar a una mayor audiencia y a los usuarios probar la red social sin barreras de acceso (Galeano, 2021; Branco, 2020; Valero, 2020).

\section{METODOLOGÍA}

El presente artículo, desde una perspectiva deductiva (Eco, 2014), refleja una investigación descriptiva y documental basada en un análisis cuantitativo y cualitativo, que ha permitido analizar parte de las fundamentaciones teóricas, que versan sobre el objeto de estudio, así como conocer las valoraciones de los usuarios acerca de los contenidos que forman parte del botón Covid-19 de TikTok. 
Contenidos digitales en la era de TikTok: percepción de los usuarios del botón COVID-19 en España

Los estudios de carácter descriptivo "narran, reseñan o identifican hechos, situaciones, rasgos, características de un objeto de estudio" (Bernal, 2010, p.113). En este caso, se analizan las valoraciones emitidas por los usuarios de TikTok sobre los contenidos difundidos en el botón Covid-19. Por otro lado, se considera un estudio documental cuando se examina la "información escrita sobre un determinado tema, con el propósito de establecer relaciones, diferencias, etapas, posturas o estado actual del conocimiento respecto al tema objeto de estudio" (Bernal, 2010, p.111). Sobre este aspecto, en el desarrollo de este artículo se consultan diferentes obras impresas y digitales que versan sobre la publicidad institucional y las redes sociales desde diferentes perspectivas, con la finalidad de relacionar y comparar los resultados obtenidos con la teoría existente sobre el tema en cuestión.

En relación a las técnicas empleadas, una investigación cualitativa implica la utilización y recogida de información relacionada con los pensamientos y los sentimientos de las personas, mediante entrevistas, experiencias personales 0 observaciones (Gil-Flores, Rodríguez-Gómez; García-Jiménez, 1996). Por otro lado, los estudios cuantitativos permiten conocer ciertos aspectos de interés sobre una población; "estudiando a cierto número de sujetos en la población (una muestra) nos podemos hacer una idea de cómo es la población en su conjunto" (Hueso; Cascant, 2012).

Estas técnicas se materializaron en una encuesta en línea, mediante un cuestionario semiestructurado, compuesto por preguntas abiertas y cerradas. Las preguntas abiertas, de carácter cualitativo, fueron recogidas y evaluadas mediante una ficha de análisis, que ha permitido recoger las valoraciones más personales de los individuos. Las preguntas cerradas, fundamentadas en la investigación presentada por MartínHerrera y Micaletto-Belda (2021), fueron recogidas en una escala tipo Likert con valores del 1 al 4 , donde 1 = muy poco (MP); 2 = poco (P); 3 = bastante (B); 4= mucho (M); 0 respuestas dicotómicas: sí o no. Los resultados fueron exportados a una hoja de cálculo, con el objetivo de analizar, interpretar y representar los datos obtenidos.

En relación a la muestra, está formada por 95 usuarios de esta plataforma, que cursan grados universitarios relacionados con la Comunicación y la Comunicación Digital. Durante la difusión del cuestionario, el botón Covid-19 de TikTok dejó de estar visible en la aplicación; hecho que ha coincidido en el tiempo con un aumento considerable de los contagios entre los jóvenes (Mouzo, 2021).

Por esta razón, entendemos que, aunque los resultados son válidos, no pueden ser extrapolados al universo completo que integran los estudiantes universitarios. No obstante, sí podrían ser replicables el estudio y el cuestionario empleado, pues pueden servir como base para analizar la funcionalidad de otras herramientas comunicativas.

En cuanto a su perfil, el $96,8 \%$ de estos encuestados poseen edades comprendidas entre los 18 y 23 años. El 56,8\% tienen entre 18-19 años; el 32,6\% entre 20-21 años; el $7,4 \%$ entre 22-23 años; el 1,1\% entre 24-25 años y, finalmente, el 2,1\% posee más de 25 años. En relación al género, han participado un 41,1\% de hombres y un 58,9\% de mujeres. En cuanto a su formación, el $62,1 \%$ de los estudiantes cursan un grado en 
Contenidos digitales en la era de TikTok: percepción de los usuarios del botón COVID-19 en España

Comunicación Digital, un 18,9\% estudian un grado en Comunicación y un 18,9\% realizan un Doble Grado en Comunicación y Comunicación Digital.

Siguiendo las indicaciones de Prensky (2011), hablamos de nativos digitales; una generación de personas jóvenes que han nacido en plena revolución tecnológica y que se relacionan socialmente de manera interconectada. Esta generación ha convertido los dispositivos portables en una extensión más de sus cuerpos y mentes. Por otro lado, la formación académica de estos estudiantes, que cursan diferentes asignaturas que versan sobre el diseño web, la analítica, la usabilidad, el diseño gráfico, el SEM o el SEO, entre otras materias, resulta idónea para analizar con propiedad las funcionalidades de esta herramienta.

Por tanto, se ha seleccionado esta muestra por un doble motivo: TikTok es una de las redes sociales más empleadas por los integrantes de la generación Z (IAB, 2021; Tamara, 2020); además, la formación académica de estos estudiantes facilita que puedan valorar los contenidos de esta aplicación desde una doble vertiente social y profesional.

Antes de la realización del cuestionario, se solicitó a los participantes que revisaran a través de sus dispositivos móviles el botón Covid-19 de TikTok y sus recursos disponibles. El profesor, con objeto de no influir en los resultados del cuestionario, se limitó a ofrecer a los estudiantes una información elemental sobre el procedimiento de entrega y envío. El trabajo de campo se realizó entre los meses de marzo y junio.

\section{ANÁLISIS Y DISCUSIÓN}

El cuestionario está dividido en tres bloques temáticos, relacionados con aspectos concretos que forman parte del botón Covid-19 de TikTok (Véase figura 1), ubicado en la parte superior derecha de la aplicación. De esta forma, el instrumento de medida se compone por las siguientes secciones: usos de TikTok, que recoge cuestiones sobre cómo interactúan los usuarios con esta red social; percepción de los usuarios de la sección "Medidas de protección", que recopila una serie de anuncios sobre el coronavirus; y análisis del apartado "Preguntas frecuentes", que contiene recursos de carácter informativo. 
Contenidos digitales en la era de TikTok: percepción de los usuarios del botón COVID-19 en España

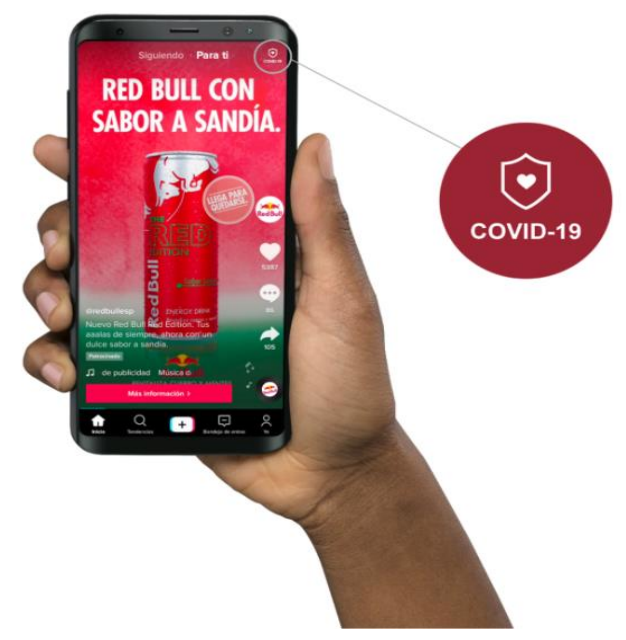

Figura 1: Botón Covid 19

Fuente: elaboración propia a partir de TikTok

\subsection{Usos de TikTok}

En esta sección, se exponen una serie de preguntas relacionadas con el consumo de esta red social entre los estudiantes (véase tabla 1), con las que se han obtenido las siguientes respuestas:

Tabla 1: Pautas de consumo en TikTok

\begin{tabular}{|c|c|c|c|c|}
\hline Preguntas & 1 (MP) & $2(P)$ & 3 (B) & $4(\mathrm{M})$ \\
\hline \multirow{2}{*}{$\begin{array}{l}\text { ¿Consideras TikTok como una fuente fiable para buscar } \\
\text { información sobre el Covid-19? }\end{array}$} & $25,3 \%$ & $55,8 \%$ & $15,8 \%$ & $3,2 \%$ \\
\hline & Sí & No & & \\
\hline ¿Consultas las fuentes oficiales de TikTok? & $15,8 \%$ & $84,2 \%$ & & \\
\hline $\begin{array}{l}\text { ¿Has compartido algún recurso de TikTok relacionado } \\
\text { con el Covid-19? }\end{array}$ & $16,8 \%$ & $83,2 \%$ & & \\
\hline \multirow[t]{2}{*}{ ¿Buscas información sobre el Covid-19 en TikTok? } & $1,1 \%$ & $98,9 \%$ & & \\
\hline & Sí & No & & \\
\hline $\begin{array}{l}\text { ¿Has visto anuncios de publicidad institucional } \\
\text { relacionados con el Covid en TikTok? }\end{array}$ & $53,7 \%$ & $46,3 \%$ & & \\
\hline $\begin{array}{l}\text { ¿Consideras útil la publicidad de TikTok relacionada con } \\
\text { el Covid-19? }\end{array}$ & $16,8 \%$ & $43,2 \%$ & $31,6 \%$ & $8,4 \%$ \\
\hline
\end{tabular}

Fuente: elaboración propia 
Contenidos digitales en la era de TikTok: percepción de los usuarios del botón COVID-19 en España

Se observa que la mayor parte de los usuarios de esta red social (Tabla 1) no perciben TikTok como una fuente fiable para localizar información relacionada con el Covid-19. Estos prosumidores han seleccionado la opción poco o muy poco $(81,1 \%)$ en relación a la cuestión planteada. Al mismo tiempo, una parte importante de estos usuarios $(84,2 \%)$ no realizan habitualmente labores de consulta en las fuentes oficiales, no comparten recursos sobre el Covid-19 $(83,2 \%)$ y no utilizan TikTok $(98,9 \%)$ para localizar información sobre el coronavirus. Estos datos preliminares ponen de manifiesto la escasa eficacia de esta red social para contribuir de forma activa en la lucha contra el Covid-19. Cabe señalar que los usuarios españoles pasan una media diaria de una hora y siete minutos consumiendo contenidos en esta plataforma y es un espacio idóneo para interaccionar con las personas más jóvenes (IAB, 2021).

En relación a las respuestas abiertas, se preguntó a los usuarios si compartían recursos en esta red social relacionados con el coronavirus. A continuación, se recogen algunas de sus opiniones:

"No he compartido ningún recurso ya que me parece mucho más fiable la información de hospitales, diarios y otros medios" (Alumno 64; A64).

"Alguna que otra vez he compartido un vídeo donde se proporcionaba, de forma resumida, el protocolo COVID o las publicaciones del BOE" (A68).

"Esta red social te hace olvidarte de la pandemia y sus consecuencias, por eso cuando me sale un TikTok del Covid lo ignoro porque no quiero saber nada" (A70).

"A pesar de que soy usuaria de la aplicación desde hace unos años, nunca me he metido en la sección Covid-19, de hecho, no sabía que existía" (A77).

Sobre la publicidad institucional emitida en TikTok, un $60 \%$ de los encuestados la consideran de poca utilidad, frente al $40 \%$ que la valoran de forma favorable. Estos datos pueden resultar relevantes en la investigación, teniendo en cuenta el profundo rechazo que la publicidad genera en una parte importante de la población (Puromarketing, 28 de octubre de 2019), y cabría plantearse si otras redes sociales obtienen los mismos niveles de aceptación entre las personas jóvenes, con el fin de identificar qué plataformas son más eficaces como soporte publicitario sobre el coronavirus.

Por otra parte, se ofrecen las valoraciones de los usuarios (véase figura 2) de la sección "Medidas de Protección" y "Preguntas y Respuestas" del botón Covid-19. 
Contenidos digitales en la era de TikTok: percepción de los usuarios del botón COVID-19 en España

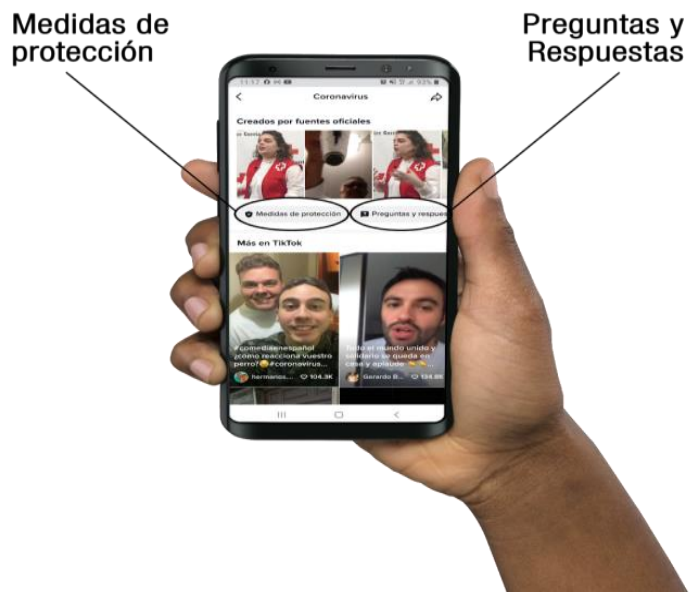

Figura 2: Secciones Botón Covid-19

Fuente: elaboración propia a partir de TikTok

\subsection{Percepción de los usuarios de la sección Medidas de Protección}

En este bloque temático, los encuestados han valorado una serie de ítems relacionados con la sección "Medidas de protección" que forman parte del botón Covid19. En la siguiente tabla (tabla 2), se aprecian las respuestas obtenidas por los usuarios.

Tabla 2: Percepción de la sección Medidas de Protección

\begin{tabular}{|l|c|c|c|c|}
\hline Preguntas & $\mathbf{1}$ (MP) & $\mathbf{2}(\mathbf{A})$ & $\mathbf{3}$ (B) & $\mathbf{4}$ (M) \\
\hline Diseño y estética & $10,5 \%$ & $36,8 \%$ & $42,1 \%$ & $10,5 \%$ \\
\hline Adaptabilidad del contenido a la plataforma & $25,3 \%$ & $28,4 \%$ & $30,5 \%$ & $15,8 \%$ \\
\hline Frecuencia de consulta & $77,9 \%$ & $15,8 \%$ & $4,2 \%$ & $2,1 \%$ \\
\hline Veracidad de las fuentes & $3,2 \%$ & $18,9 \%$ & $41,1 \%$ & $36,8 \%$ \\
\hline Utilidad de los contenidos & $11,6 \%$ & $33,7 \%$ & $37,9 \%$ & $16,8 \%$ \\
\hline Legibilidad de los recursos & $21,1 \%$ & $30,5 \%$ & $33,7 \%$ & $14,7 \%$ \\
\hline Actualización de los contenidos & $16,8 \%$ & $27,4 \%$ & $33,7 \%$ & $22,1 \%$ \\
\hline & Sí & No & & \\
\hline ¿Compartirías este contenido? & $40 \%$ & $60 \%$ & & \\
\hline
\end{tabular}

Fuente: elaboración propia 
Contenidos digitales en la era de TikTok: percepción de los usuarios del botón COVID-19 en España

En esta sección, se observa que una parte importante de los estudiantes $(47,3 \%)$ no valoran de forma favorable el diseño y la estética de este apartado, frente a un $52,6 \%$ que sí lo hace. Se trata de un dato relevante, pues el diseño es uno de los factores más importantes que intervienen en el éxito de una determinada aplicación móvil (Ruiz; Polo, 2012). En la siguiente imagen (figura 3), se puede apreciar cómo es esta parte de la aplicación:

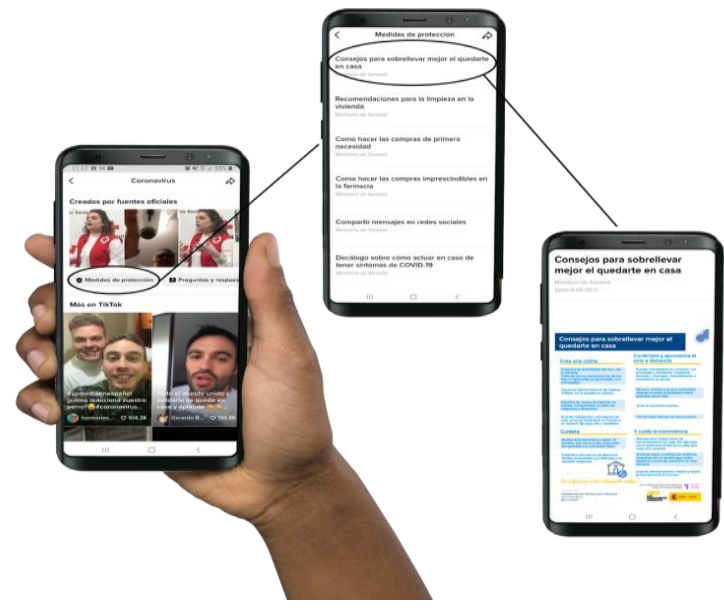

Figura 3: Exposición móvil de "Medidas de protección" Fuente: elaboración propia a partir de TikTok

En relación al contenido, el $53 \%$ opina que está poco o muy poco adaptado a la red social. Además, el $51,6 \%$ ha optado por asignar una valoración baja al ítem relacionado con la legibilidad de los contenidos. En la siguiente infografía, se muestra uno de los recursos (figura 4) de la aplicación: 


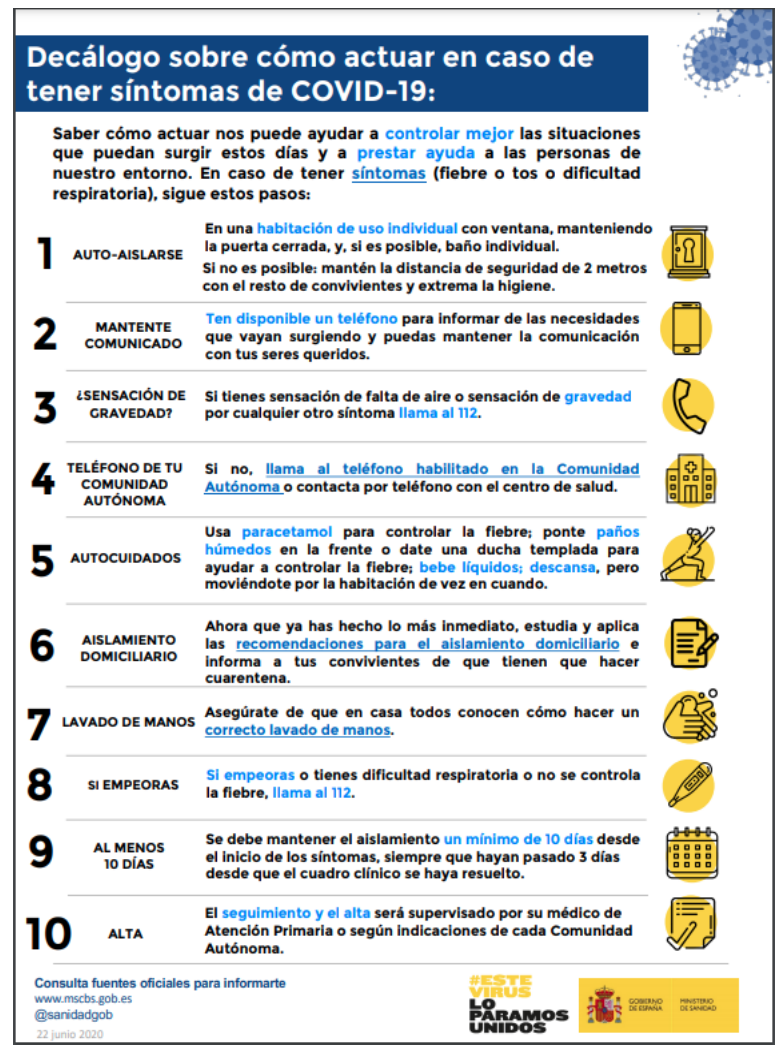

Figura 4: Documento original sin adaptación responsive

Fuente: TikTok

Por otro lado, la frecuencia de consulta de este apartado es relativamente baja $(93,7 \%)$ y que un $60 \%$ de estas personas no estarían dispuestas a difundir estos recursos. Sin embargo, el $77,9 \%$ de los estudiantes consideran que se trata de una fuente fiable y un $54,7 \%$ consideran de utilidad estos contenidos. Por tanto, se advierte que puede existir una relación entre el escaso uso de esta herramienta para prevenir el contagio del coronavirus y el diseño y la adaptación del contenido a la misma.

Por otro lado, se ha preguntado a los usuarios qué opinaban acerca de esta sección y qué aspectos mejorarían. Estas son algunas de sus aportaciones:

"Visualmente no es muy estética ya que la letra es pequeña y al haber tanto texto hay poco espacio entre un párrafo y otro. Además, en algunas recomendaciones el contenido no da la sensación de que esté ordenado y se hace un poco pesado. Por otro lado, el uso de distintos colores distrae un poco la atención del mensaje que se quiere transmitir. El logo para acceder a esta sección me parece pequeño y pasa desapercibido" (A22).

"El punto más desfavorable de esta sección es la poca adaptabilidad del contenido a la plataforma. TikTok es una red social de videos cortos, hecho que choca bastante con la información escrita que aparece en esta sección. Creo que hubiese sido más acertado hacer videos cortos, o incluso algún reto relacionado con el conocimiento de las medidas sanitarias para prevenir el Covid-19. Además, la información, aunque 
Contenidos digitales en la era de TikTok: percepción de los usuarios del botón COVID-19 en España

interesante y útil, no invita a ser leída, y se puede hacer demasiado larga y pesada" (A28).

"Me parece súper interesante, pero creo que no están muy adaptados a la plataforma" (A38).

"Considero que esta sección es muy útil, no cabe duda, pero no creo que cumpla su objetivo comunicativo. Personalmente nunca he entrado a esa sección y estoy seguro de que mucha gente tampoco. En mi opinión no se "publicita" mucho la existencia de ese botón y sección" (A41).

"Me parece estupendo que TikTok ofrezca una sección especializada en el tema, pues el público objetivo de esta red social es muy amplio y muy variado" (A66).

"Se debería adaptar al formato natural de la aplicación: vídeos cortos editados" (A94).

\subsection{Percepción de los usuarios de la sección Preguntas y Respuestas}

Finalmente, los usuarios han valorado la sección "Medidas de protección" (véase figura 5) y se han obtenido las siguientes respuestas recogidas en la tabla 3.

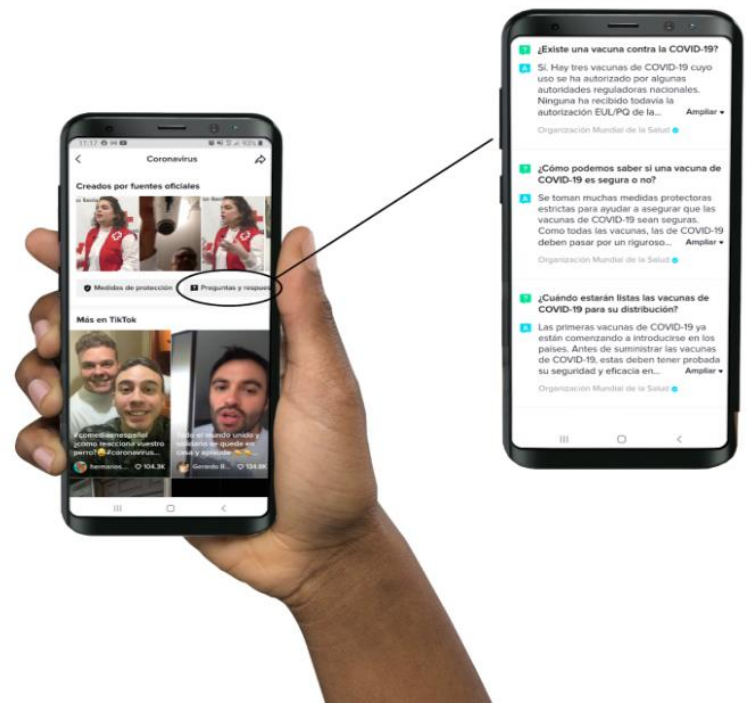

Figura 5: Preguntas y respuestas

Fuente: elaboración propia a partir de TikTok 
Contenidos digitales en la era de TikTok: percepción de los usuarios del botón COVID-19 en España

Tabla 3: Percepción de la sección Preguntas y Respuestas

\begin{tabular}{|l|c|c|c|c|}
\hline Preguntas & $\mathbf{1}$ (NA) & $\mathbf{2}$ (PA) & $\mathbf{3}$ (BA) & $\mathbf{4}$ (CA) \\
\hline Diseño y estética & $11,6 \%$ & $32,6 \%$ & $41,1 \%$ & $14,7 \%$ \\
\hline Adaptabilidad del contenido a la plataforma & $21,1 \%$ & $25,3 \%$ & $37,9 \%$ & $15,8 \%$ \\
\hline Frecuencia de consulta & $70,5 \%$ & $18,9 \%$ & $9,5 \%$ & $1,1 \%$ \\
\hline Veracidad de las fuentes & $4,2 \%$ & $15,8 \%$ & $43,2 \%$ & $36,8 \%$ \\
\hline Utilidad de los contenidos & $14,7 \%$ & $21,1 \%$ & $47,4 \%$ & $16,8 \%$ \\
\hline Legibilidad de los recursos (información Covid-19) & $7,4 \%$ & $22,1 \%$ & $47,4 \%$ & $23,2 \%$ \\
\hline Actualización de los contenidos & $9,5 \%$ & $31,6 \%$ & $41,1 \%$ & $17,9 \%$ \\
\hline & Sí & No & & \\
\hline ¿Compartirías este contenido? & $41,1 \%$ & $58,9 \%$ & & \\
\hline
\end{tabular}

Fuente: elaboración propia

En esta sección los datos son similares a los recogidos en la tabla 2. Sin embargo, existen algunas diferencias.

En relación al diseño y la estética (véase figura 5), un 55,8\% de los jóvenes valoran positivamente el apartado de Preguntas y Respuestas, frente a un $44,2 \%$ que lo entiende como poco o nada atractivo. En lo relativo a la adaptabilidad del contenido a la plataforma, poco más de la mitad de los encuestados $(53,5 \%)$ considera que se adecúa a las características de esta red social, mientras que un $46,4 \%$ piensa que no lo hace.

Otro dato interesante para analizar es la frecuencia de consulta. Resulta llamativo que casi 9 de cada 10 estudiantes $(89,4 \%)$ entre poco o ni siquiera acceda a esta sección que ofrece el botón Covid-19 de TikTok. Por otro lado, al preguntar sobre la veracidad de las fuentes, un $80 \%$ ha valorado positivamente este aspecto, considerando que entidades como el Ministerio de Sanidad o la Organización Mundial de la Salud (quienes completan el contenido de esta sección) cumplen con la garantía de ser un emisor veraz.

Respecto a los contenidos, la encuesta ha arrojado varios datos de interés. Sobre la utilidad de los mismos, un $64,2 \%$ afirma que son bastantes o muy útiles, frente a poco más de un tercio $(35,8 \%)$ que considera que no lo son. La legibilidad de los recursos es otro de los aspectos que el $70,6 \%$ de los adolescentes determina como correcta, así como la actualización de los contenidos, ya que un $59 \%$ la valora de forma favorable. 
Contenidos digitales en la era de TikTok: percepción de los usuarios del botón COVID-19 en España

Por último, se les consultó a los estudiantes si ellos mismos compartirían el contenido de esta sección de Preguntas y Respuestas. Similar a la respuesta obtenida en el apartado Medidas de Protección, casi 6 de cada 10 jóvenes $(58,9 \%)$ no daría a conocer esta información a través de sus perfiles.

Para conocer la opinión de los encuestados acerca de esta sección, se han planteado cuestiones relacionadas con la mejora de la aplicación. Estas fueron algunas de sus aportaciones a la investigación:

"Es una sección más cercana a los usuarios ya que son preguntas y respuestas por lo tanto, se asemeja a un contacto más directo. Sin embargo, solo hay una serie de preguntas por lo tanto la información es limitada y los usuarios no pueden poner sus propias preguntas lo cual no abarca a todas las cuestiones que alguien puede tener sobre el covid-19" (A9).

"Mejoraría los colores, añadiría imágenes, sonido... Considero que una forma efectiva podría ser que la propia plataforma y cuenta oficial de TikTok publicara vídeos en su formato, es decir, cortos entretenidos y con música comentando las medidas del COVID-19 y sería una buena opción utilizar como imagen de esta campaña COVID a los principales TikTokers a nivel nacional e internacional, ya que en el momento que en la pantalla principal te aparece un rostro conocido de la plataforma, animará al usuario a continuar viéndolo" (A17).

"Como en la anterior sección, creo que sería más acertado hacer uso de los recursos audiovisuales, es decir, utilizar los videos y la edición que te permite ejecutar la aplicación para difundir esta información. De hecho, existe la posibilidad de hacer videos que sirvan como respuesta a una pregunta. Además, algo que tampoco me ha gustado es que la respuestas que dan, al ser muy largas, siempre hay que darles al botón "ampliar", pero luego no se puede volver a menguar la sección, por lo que hay que hacer un "scroll" excesivamente largo. En definitiva, cambiaría el diseño de la sección al completo para adaptarlo mejor al de la aplicación" (A27).

"Daría mayor visibilidad al botón del Covid-19 para que tuviesen los usuarios mayor interacción con este apartado de la aplicación. Dentro del apartado separaría mucho más lo que son los contenidos audiovisuales de las infografías y preguntas frecuentes y daría mayor visibilidad a las fuentes, ya que estas mismas vienen directamente del ministerio de sanidad. Por otra parte se debería de poder hacer zoom en las diferentes infografías para una legibilidad mejor" (A82).

"Esta sección me gusta más que la anterior porque visualmente se percibe mejor y se leen las preguntas y respuestas sin problema alguno" (A94). 
Contenidos digitales en la era de TikTok: percepción de los usuarios del botón COVID-19 en España

\section{CONCLUSIONES}

Las redes sociales demuestran tener un papel trascendental en la difusión de contenidos que versan sobre asuntos de interés general. En su conjunto, representan un canal de comunicación directo que permite a las distintas autoridades sanitarias conectar con su audiencia sin ambages. Estas plataformas pueden propagar mensajes de distinta naturaleza con la finalidad de provocar una determinada reacción en el receptor. Por esta razón, constituyen uno de los activos más importantes en la pandemia provocada por el coronavirus.

El botón Covid-19 de TikTok podría constituir una importante fuente de información para ayudar a la población a frenar la expansión del coronavirus, pues los usuarios consideran de gran utilidad los contenidos digitales de la aplicación que versan sobre este asunto. Sin embargo, se ha comprobado en los resultados alcanzados que la frecuencia de consulta es relativamente baja.

Del mismo modo, son muchas las instituciones sanitarias que poseen dificultades para desarrollar acciones comunicativas eficaces, informativas o publicitarias, que provoquen un cambio de comportamiento en el receptor. Cada organización debe diseñar el método más adecuado para conectar con su audiencia según su perfil psicográfico (Echazarreta, 2020). En el caso analizado, es necesario plantearse cómo mejorar la accesibilidad a estos recursos de especial interés en un contexto de crisis sanitaria global. Se observa en las valoraciones emitidas por los encuestados, que es necesario cuestionar la adaptación de estos recursos a la plataforma y al tipo de público, siguiendo las recomendaciones consultadas en el estudio (Marcelino, 2015; De-las-Casas, 2020; Cancelo; Gadea, 2013). Todo discurso que aspire a consolidarse debe estar adecuado a la naturaleza y la identidad de cada red social (Martín-Ramallal y Micaletto-Belda, 2021).

TikTok apuesta por crear y difundir vídeos, de carácter efímero, relacionados con distintas temáticas. Como propuesta de mejora, estos contenidos nativos, publicitarios e informativos, podrían adquirir mayor aceptación si se ajustaran más al ambiente natural de la plataforma, con el objetivo de reforzar o cambiar determinadas comportamientos de las personas mediante el uso de la razón y las emociones (Cortés, 2009; Bassat, 2006; Xifra, 2020); prevenirlas y protegerlas sobre acontecimientos de interés público (Martínez, 2015).

Por todo lo anterior, la investigación concluye que, en una situación de crisis como la derivada del Covid-19, no se ha aprovechado plenamente el potencial de esta herramienta para dejar pregnancia de mensajes institucionales de interés general. Por ello, se recomienda que en casos de necesaria difusión de mensajes asertivos, se adapten los mismos de manera taxativa al ecosistema digital para el que están planteados con el fin de lograr sus metas, que no es otra que la de crear conciencia colectiva por un bien general, en este caso, la salud y la protección social.

En futuras líneas de investigación, resultaría apropiado analizar la funcionalidad y la capacidad de transmitir mensajes a la población de otros instrumentos de información 
Contenidos digitales en la era de TikTok: percepción de los usuarios del botón COVID-19 en España

empleados en la gestión sanitaria del coronavirus, como sería el caso de redes como Instagram o Facebook, que poseen herramientas parecidas. Por otro lado, sería interesante conocer cómo emplean instituciones, como el Ministerio de Sanidad, su cuenta oficial en TikTok para concienciar sobre los efectos del Covid-19. Se podrían estudiar, entre otros aspectos: el nivel de interacción con los seguidores, los efectos generados por sus mensajes o el tipo de contenido desarrollado.

\section{REFERENCIAS}

Aguado-Guadalupe, G. (2018). Las relaciones Prensa-Estado en el reparto de publicidad institucional en España. Estudios sobre el Mensaje Periodístico, 24(2), 993-1005. https://doi.org/10.5209/ESMP.62198

Almansa-Martínez, A., Fonseca-Bogotá, O., Castillo-Esparcia, A. (2013). Redes sociales y jóvenes. Uso de Facebook en la juventud colombiana y española. Comunicar: Revista Científica de Comunicación y Educación, 20(40), 127-135. https://doi.org/10.3916/C40-2013-03-03

Bassat, L. (2006). El libro rojo de la publicidad (ideas que mueven montañas). DEBOLSILLO

Bernal, C. A. (2010). Metodología de la investigación para administración y economía. Pearson

Branco, A. (15 de junio de 2020). ¿Por qué TikTok tiene tanto éxito? Éstas son las 5 razones. El Español. https://www.elespanol.com/omicrono/software/20200615/tiktokexito-razones/497201249 0.html

Cancelo, M., Almansa, A. (2013). Estrategias comunicativas en redes sociales. Estudio comparativo entre las universidades de España y México. Historia y comunicación social, 18, 423-435. https://revistas.ucm.es/index.php/HICS/article/view/44339

Cancelo, M., Gadea, G. (2013). Empoderamiento de las redes sociales en las crisis institucionales. Vivat academia, 21-33. https://doi.org/10.15178/va.2013.124.21-33

Castells, M. (2009). Comunicación y poder. Alianza

Castillo-Esparcia, A. (2010). Introducción a las Relaciones Públicas. Instituto de Investigación en Relaciones Públicas.

Castillo-Esparcia, A., Fernández-Souto, A. B., Puentes-Rivera, I. (2020). Comunicación política y Covid-19. Estrategias del Gobierno de España. Profesional de la información, 29(4), e290419. https://doi.org/10.3145/epi.2020.jul.19 
Contenidos digitales en la era de TikTok: percepción de los usuarios del botón COVID-19 en España

Cortés, A. (2009). Publicidad institucional y cultura de paz en los Países Bajos. Revista Latina de Comunicación Social, 12(64), 612-631. http://www.revistalatinacs.org/09/art/849 UMA/50 67 Cortes.html

Cortés, A. (2011). La publicidad institucional en España. Una década en perspectiva. Razón y palabra, 16(75). https://doi.org/10.4185/RLCS-64-2009-849-612-631

De-las-Casas, J. (17 de diciembre de 2020). Cómo ha cambiado la comunicación entre empresas y consumidores. Expansión. https://www.expansion.com/economia/2020/12/17/5fda76ed468aeb4f638b45ef.html

Echazarreta, B. (2020). Del buenismo al drama en los spots para jóvenes: La campaña perfecta es como un antibiótico. ABC. https://www.abc.es/sociedad/abci-buenismodrama-spots-para-jovenes-campana-perfecta-como-antibiotico202011260124 noticia.html?ref=https\%3A\%2F\%2Fwww.google.com\%2F

Eco, U. (2014). Cómo se hace una tesis. Editorial Gedisa

Flores-Vivar, J. M. (2009). Nuevos modelos de comunicación, perfiles y tendencias en las redes sociales. Comunicar, 17(33), 73-81. https://doi.org/10.3916/c33-2009-02$\underline{007}$

Gallardo-Vera, L., Micaletto-Belda, J.P. (2018). Hacia una definición de comunicación institucional en situaciones de crisis. Revista Observatório, 4(1), 437-465. https://doi.org/10.20873/uft.2447-4266.2018v4n1p437

Galeano, S. (21 de junio 2021). Cómo funciona el algoritmo de TikTok explicado por TikTok. Marketing 4 eCommerce. https://marketing4ecommerce.net/algoritmo-detiktok-explicado-tiktok/

Gil, Flores, J., Rodríguez-Goméz, G., García-Jiménez, E. (1996). Metodología de la investigación cualitativa. Aljibe

Hueso, A., Cascant, M. J. (2012). Metodología y técnicas cuantitativas de investigación. Universitat Politècnica de València

IAB (2020). Estudio de Redes Sociales 2020. https://iabspain.es/presentacion-estudioredes-sociales-2020/

IAB (2021). Estudio de Redes Sociales 2021. https://iabspain.es/estudio/estudio-deredes-sociales-2021/

Igartua, J. J., Ortega-Mohedano, F., Arcila-Calderón, C. (2020). Usos de la comunicación en los tiempos del coronavirus. Un estudio transcultural. El profesional de la información (EPI), 29(3). https://doi.org/10.3145/epi.2020.may.18

Kotler, P., Armstrong, G. (2013). Fundamentos de marketing. Pearson educación. 
Contenidos digitales en la era de TikTok: percepción de los usuarios del botón COVID-19 en España

Ley 29/2005, de 29 de diciembre, de Publicidad y Comunicación Institucional. Boletín Oficial del Estado. https://www.boe.es/buscar/pdf/2005/BOE-A-2005-21524consolidado.pdf

Luecke, R. (2005). Gestión de crisis convertirlas en oportunidades. Ediciones Deusto.

Marcelino, G. (2015). Migración de los jóvenes españoles en redes sociales, de Tuenti a Facebook y de Facebook a Instagram. La segunda migración. ICONO 14, Revista de comunicación y tecnologías emergentes, 13(2), 48-72. https://doi.org/10.7195/ri14.v13i2.821

Martínez, E. (2012). Publicidad Institucional de las Administraciones Públicas: marco jurídico y controversias. Comunicación y Hombre, (8), 50-63. https://portalderevistas.ufv.es/index.php/comunicacionyhombre/article/view/142/141

Martínez, E. (2015). Estado de la cuestión de la Publicidad Institucional en España (2006-2012). Poliantea, 11(21), 105-128. https://doi.org/10.15765/plnt.v11i21.705

Martín-Herrera, I., Micaletto-Belda, J. P. (2021). Opiniones y actitudes de los estudiantes universitarios de Comunicación ante las fake news. Diagnóstico en un ecosistema docente. Comunicación y hombre: revista interdisciplinar de ciencias de la comunicación y humanidades, (17), 193-206. https://doi.org/10.32466/eufvcyh.2021.17.661.193-206

Martín-Ramallal, P., \& Micaletto-Belda, J. P. (2021). Tiktok, red simbiótica de la generación z para la realidad aumentada y el advergaming inmersivo. Revista de Comunicación, 20(2), 223-242.

Ministerio de Sanidad (2020). El Ministerio de Sanidad estrena cuenta oficial en la red social TikTok. https://www.mscbs.gob.es/gabinete/notasPrensa.do?id=5047

Mohsin, M. (1 de julio de 2021). 10 Estadísticas de Tiktok que debes conocer en 2021. Oberlo. https://www.oberlo.es/blog/estadisticas-tiktok

Monferrer, D. (2013). Fundamentos de marketing. Universitat Jaume I. http://dx.doi.org/10.6035/Sapientia74

Moreno, S. (2020). ¿Son efectivas las campañas agresivas sobre la covid entre los jóvenes? Preguntamos a estudiantes y a expertos. El País, 25 de noviembre. https://verne.elpais.com/verne/2020/11/23/articulo/1606126048 182461.html

Mouzo, J. (2021). El aumento de contagios entre jóvenes acelera la transmisión de la Covid en España. El País. https://elpais.com/sociedad/2021-06-28/el-aumento-decontagios-entre-jovenes-acelera-la-transmision-de-la-covid-en-espana.html

Olivares-García, F. J., Méndez-Majuelos, I. (2020). Análisis de las principales tendencias aparecidas en TikTok durante el periodo de cuarentena por la COVID-19. Revista Española de Comunicación en Salud, (1) 243-252. https://doi.org/10.20318/recs.2020.5422 
Contenidos digitales en la era de TikTok: percepción de los usuarios del botón COVID-19 en España

Orihuela-Colliva, J. L. (2008). Internet: la hora de las redes sociales. Nueva Revista de Política, Cultura y Arte, 119, 57-62. https://hdl.handle.net/10171/2962

Orozco, J. A. (2010). Comunicación estratégica para campañas de publicidad social. Pensar la publicidad, 4(2), 169-190. https://revistas.ucm.es/index.php/PEPU/article/view/PEPU1010220169A

Ruiz, S., Polo, D. (2012). La realidad aumentada como nuevo concepto de la publicidad online a través de los smartphones. Razón y palabra, (80). 293-307. https://www.revistarazonypalabra.org/index.php/ryp/article/view/492

Piñuel, J. L. (1997). Teoría de la comunicación y gestión de las organizaciones. Editorial Síntesis, S.A.

Prensky, M. (2011). Enseñar a nativos digitales. SM.

Puromarketing (2019). Demasiados anuncios, muy molestos y poco creativos: por qué cada vez más gente odia la publicidad. 28 de octubre. https://www.puromarketing.com/9/32784/demasiados-anuncios-muy-molestos-pococreativos-cada-vez-mas-gente-odia-publicidad.html

Selva-Ruiz, D. Martín-Ramallal, P. (2019). Realidad virtual, publicidad y menores de edad: otro reto de la cibersociedad ante las tecnologías inmersivas. ICONO 14, Revista de comunicación y tecnologías emergentes. 17(1), 83-110. https://doi.org/10.7195/ri14.v17i1.1234

Sterzer, S. (2020). Impacto del coronavirus en el sistema educativo: ejemplos en el continente asiático. Red Sociales. Revista del Departamento de Ciencias Sociales, 7(2), 64-74. http://ri.unlu.edu.ar/xmlui/handle/rediunlu/751

Suarez, F. (2020). Publicidad en tiempos del COVID-19. ¿Cómo empezamos? ¿Cómo seguimos? CIMEC. https://www.cimec.es/publicidad-en-tiempos-del-covid-19-comoempezamos-como-seguimos/

Tamara, N. (2020). TikTok. La aplicación favorita durante el aislamiento. Revista Argentina de Estudios de Juventud (14). 1-9. https://doi.org/10.24215/18524907e044

Valero, C. (2020). La fórmula de la atracción inmediata de TikTok: contenidos en abierto para enganchar y un potente algoritmo para la fidelización. Xataka, https://www.xataka.com/servicios/formula-atraccion-inmediata-tiktok-contenidosabierto-para-enganchar-potente-algoritmo-para-fidelizacion

Verne (2020). Sanidad llega a TikTok para intentar concienciar a los jóvenes sobre el coronavirus.

País.

https://verne.elpais.com/verne/2020/09/09/articulo/1599649765 147985.html 
Contenidos digitales en la era de TikTok: percepción de los usuarios del botón COVID-19 en España

Xifra, J. (2020). Comunicación corporativa, relaciones públicas y gestión del riesgo reputacional en tiempos del Covid-19. El profesional de la información (EPI), 29(2). 118. https://doi.org/10.3145/epi.2020.mar.20

\section{AUTORES}

\section{Dr. Juan Pablo Micaletto-Belda 1}

Profesor y coordinador de curso de los Grados universitarios en Comunicación y Comunicación Digital del Centro Universitario San Isidoro, adscrito a la Universidad Pablo de Olavide

Orcid ID: https://orcid.org/0000-0002-5424-6968

\section{Dr. Pablo Martín-Ramallal 2}

Profesor de los Grados universitarios en Comunicación y Comunicación Digital del Centro Universitario San Isidoro, adscrito a la Universidad Pablo de Olavide

Orcid ID: https://orcid.org/0000-0003-3055-7312

\section{Alba Merino Cajaraville 3}

Profesor de los Grados universitarios en Comunicación y Comunicación Digital del Centro Universitario San Isidoro, adscrito a la Universidad Pablo de Olavide

Orcid ID: https://orcid.org/0000-0001-9994-456X 